\title{
Separating law from Geography in GIS-based eGovernment services
}

\author{
ALEXANDER BOER, TOM VAN ENGERS, ROB PETERS, and \\ RADBOUD WINKELS
}

Leibniz Center for Law, University of Amsterdam, Oudemanhuispoort 4, PO Box 1030Amsterdam, 1030 BA, Netherlands

E-mails:aboer@uva.nl;vanengers@uva.nl; peters@lri.jur.uva.nl;winkels@uva.nl

\begin{abstract}
The Leibniz Center for Law is involved in the project Digitale Uitwisseling Ruimtelijke Plannen [DURP (http://www.vrom.nl/durp); digital exchange of spatial plans] which develops a XML-based digital exchange format for spatial regulations. Involvement in the DURP project offers new possibilities to study a legal area that hasn't yet been studied to the extent it deserves in the field of Computer Science \& Law. We studied and criticised the work of the DURP project and the Dutch Ministry of internal affairs on metadata for regulatory documents, and made an inventory of issues related to legal knowledge representation that it felt were not sufficiently covered by current initiatives in the Geographic Information Systems (GIS) field. This inventory was an input to the DURP standardisation effort. In a second phase of the project we extended the ${ }^{M E T A}$ Lex XML schema (cf. Boer et al. 2002; Boer et al. 2003) for 'regular' legal sources that we developed in the past for geospatial regulatory information, in order to support exchange of spatial regulations, including the associated geospatial information in the form of maps. We developed a prototype application and demonstrated how the spatial planning information in GML can be combined with XML with only minimal changes, using the Web Ontology Language (OWL). This paper describes our experiences.
\end{abstract}

Key words: GIS, GML, law, norms, semantic Web

\section{Introduction}

Geospatial data is a very valuable and versatile resource, and finds it's way into navigation software, real estate search engines, etc. It is not surprising to learn that there are widely established international standards in this field.

A major part of the high quality geospatial data used in the GIS world is collected by governments and actually represents normative statements, positions, and titles relating to space rather than representation of existing 'real' geographic features. The term geospatial should be understood in this 
context: geospatial data consists of spatial data describing geographic objects and features and of other objects and features that are - directly or indirectly - geospatially referenced.

Geospatial data capturing titles and responsibilities are often used by third parties as if they describe the things that are there. A property title and a building permit for instance become a house in the translation of a cadastral database of claims and titles to geospatial data. For many areas of the world cadastral and urban development maps are simply the best source of information available about what the real situation on the ground might look like.

Within the academic spatial planning community there is some awareness of this problem, and there have been attempts to capture this distinction between normative statements relating to space and real spatial objects. Attempts in this direction however rarely take into account that the legal field initiates its own efforts to standardize legal sources, and that these legal sources sometimes have a implicit geospatial component, even if it doesn't use maps.

When designing open XML standards it is important to recognize the limits of the type of information that is being standardised; Legal communities should not concern themselves with geospatial objects, and the GIS community should exercise restraint when classifying geospatial 'constitutional facts' that are derived from law and social processes grounded in the legal system. When designing a standard for the explicit purpose of communicating legal sources to the population, the dual nature of these geospatial 'constitutional facts' should be taken into account. An open standard for these objects mixes conventions from the GIS field and the legal field.

The Leibniz Center for Law is currently involved in the project Digitale Uitwisseling Ruimtelijke Plannen (DURP; digital exchange of spatial plans) which develops a digital exchange format for spatial regulations - in the broadest sense. The project is coordinated by the Ministry of Housing, Spatial Planning, and the Environment (VROM), and it involves diverse parties such as the Association of Cooperating Municipalities, the provinces, the Union of Water Control Boards (waterschappen) and a number of others that cooperate on a more or less voluntary basis.

For the Leibniz Center for Law, having designed the ${ }^{\text {META }}$ Lex $^{1}$ XML schema (cf. Boer et al. 2002; Boer et al. 2003) for 'regular' legal sources, involvement in the DURP project offers new possibilities to study a legal area that hasn't been yet studied to the extent it deserves in Computer Science \& Law. In Section 4 we will also discuss the possibility of extending the ${ }^{\text {META }}$ Lex XML standard in order to support exchange of spatial regulations, including the associated geospatial information, under the umbrella of CEN/ ISS in the Estrella IST project. 
Past projects like $A D D$ Wijzer $^{2}$ (Peters and Van Engers 2004; Wilson and Peters 2004) show that potentially valuable services can be delivered to citizens if only the legal sources of the spatial regulations would be available in the right form. The Legal Atlas developed in this project is discussed in Section 2.3. The Legal Atlas has been partially reimplemented based on OWL GML 2.0, relevant Dutch standards, and META Lex XML.

The Leibniz Center made an inventory of typically legal issues we feel are not sufficiently covered by current initiatives in the Geographic Information Systems (GIS) field. Adequate support for facilities that are common in the legal field - text search, classification with taxonomies of legal concepts, versioning - should be a part of a standard for spatial legislation.

In this paper we describe some features of this peculiar legal domain, and compare this domain with other legal domains. A number of regulative standardisation initiatives are being reviewed, including those aimed at harmonisation of metadata of the Dutch Ministry of internal affairs (BZK) and the spatial zoning interoperability initiatives (IMRO and DURP) of the Ministry of Spatial affairs. We discuss some shortcomings of the traditional GIS perspective on spatial planning sources, and explain why input from a legal perspective is needed.

\subsection{LEGISLATION AND GEOSPATIAL OBJECTS}

Legislation always has a spatial component, mediated through the concept of jurisdiction. Jurisdiction refers both to a power or competence - to legislate, to apply or interpret legislation, or to take administrative decisions based on legislation - and the territory within which this power can be exercised.

This power can be delegated, by means of legislation, to a dependent legislator which has jurisdiction in a territory that is included in the territory of the delegating legislator. Legislation of the EU, the state, the province or region, and the municipality is in a sense linked to a space to which it applies. But this link to a geospatial object is usually implicit; It is for example taken for granted that Dutch legislation applies in Dutch territory and that across the border in the east German legislation applies.

In a specific domain of law - spatial planning - the concept space plays a central role. Since this type of legislation specifically aims at regulating the use of space, that space is indicated explicitly. Space is so dominant in this field that a legislative culture has grown that distinguishes itself from the dominant legislative drafting culture in other legal domains. While in the regular legislative drafting processes legislative drafters focus on written norms, the definition of the things the norms are about, and the way those norms are described - following certain rules, regulations, and traditions the drafters of spatial regulations focus on drawing good maps. 
Regulations whose major conditions on applicability can be naturally displayed on maps have a number of specific advantages over other regulations; Restrictions and rights naturally associated with geospatial objects are more easy to find because:

Presentation: Everybody knows and understands maps; It is a familiar user interface paradigm, requiring only common sense knowledge from the user. The geospatial coherence of geospatial objects creates inescapable logical constraints between regulations. These logical constraints are as fundamental to understanding that domain, as understanding that the economic world is made up of transactions between agents where money is exchanged is fundamental to understanding taxation law.

Territorial jurisdiction: Because legislators tend to have jurisdiction in a specific area, and hierarchical relations between legislators are mirrored in spatial inclusion relationships, it is easy to find all legislators that could possibly have something to say about the usage of a specific parcel of land. Compare this with deciding which legislators could have jurisdiction over a sales transaction: jurisdiction could be decided by factors like:

- Nationality of involved parties,

- location of relevant events, and

- the use of mediating technologies like computers.

This apparent simplicity in spatial planning is also misleading: people tend to believe that having a permit of the municipality grants them a valid title to act, but this is not necessarily the case.

Adjacency: Occasionally regulations have indirect effects on other things one would not have thought about. To design a fire pump for a ship, for instance, one has to know about rules pertaining to power systems, the ejection capacity of the ship as a whole, and the required pressure at hydrants. If you break a leg at a construction site there are many rules in different fields of law (criminal law, tort law, labour law) that might apply to what happened to you.

A nice feature of the spatial planning domain is that indirect effects are almost always mediated by adjacency in space, which means that rules and restrictions can be naturally grouped by area of effect. In other domains of law, useful classifications of rules and restrictions so that they can easily found in a natural 'place' are harder to produce. Most classifications of sources of law used in the legal field are of little assistance to the citizen armed with only common sense knowledge in finding the rules that apply to the thing that happened to him or the thing he wants to do.

A number of advantages for eGovernment follow naturally from the use of map data: 
Transparency of metadata: Retrievability of documents is highly dependent on whether the user understands the metadata attached to the legal documents. Choosing good descriptive keywords for a document is perceived as hard and subjective, while attaching spatial references to a document is considered easy and objective.

Citizen-centred organisation of data: The coloured map is a proven user interface for selecting the territorial jurisdictions the user intends to interrogate. The user interface of GIS technology makes it natural to view legal information from different territorial jurisdictions in the same user interface, and makes it possible to activate different layers of distinctive (coloured) representations of restrictions at the same time in one interface to answer queries of the form "in which location will I have the least problems with legal constraints or permits when I perform this or that action?". This is a tangible improvement over the classical government-centred organisation of data, which typically requires text search in local regulations at municipal websites (cf. Peters and Van Engers 2004; Wilson and Peters 2004).

Using maps has the great advantage that maps provide both the legislative drafters and the addressees (users) of the regulation with a means of communication that is easy to understand, but maps are not necessarily the primary access method to a legal source. There are circumstances in which it is more appropriate to access specific geospatial objects on maps through text retrieval, as lawyers working in the field will be able to explain: to find a 'similar case' one does not want to search for geospatial objects with the same properties from the point of view of the law of interest, regardless of where they are, and see whether relevant case law is attached to them.

Focusing too much on primary access through the map also has drawbacks. These drawbacks become apparent when the government wants to create standardised legal information systems that support legislative drafting, information exchange, version management, and eServices. based on generic legal theory.

To be able to use just one standardised form, in which spatial regulations can be expressed, exchanged and stored, it is necessary to separate the representation form (the map-based view) from the regulatory content (the actual norm) and to treat them as equals.

\subsection{RELEVANCE}

The Ministry of the Interior is responsible for the main eGovernment portal ${ }^{3}$ and they are tasked with improving the accessibility of government information. A recent project is called the watmagwaarkaart, a neologism that 
literally translates as the "what-is-allowed-where-map". The Dutch eGovernment programme leaders think that maps are relevant for the national search portal to inform citizens about rules and regulations of local governments in a way that makes sense to them.

The Leibniz Center investigated over 200 URLs pointing to geographically related information for the Dutch Ministry of Interior. Classification of the spatial information accessible through the 200 URLs shows that the vast majority of all maps used on municipality websites are related to the representation of local regulations, and the largest number are those related to zoning or spatial plans and permits, as figure 1 shows. This is also the reason why the Ministry of Spatial Affairs is trying to standardise spatial planning information through the DURP programme mentioned before. It also shows the relevance of this article. There is a marriage between law and maps in the making which seems to be developing rapidly on its own, without paying much attention to lessons learned in other areas of standardisation of law.

The standardisation effort for spatial planning in the Netherlands predates the digital age: The first version of the voluntary standard was mostly concerned with the standardisation of the way information is displayed on maps. Basic conventions of this standard like the use of the colour yellow for areas designated for residential use are familiar to citizens in the Netherlands. The second voluntary standard, which was developed over the last years deals with digital standardisation and updates the previous standard by standardizing representation issues which have become pressing in an era of Internet and GIS.

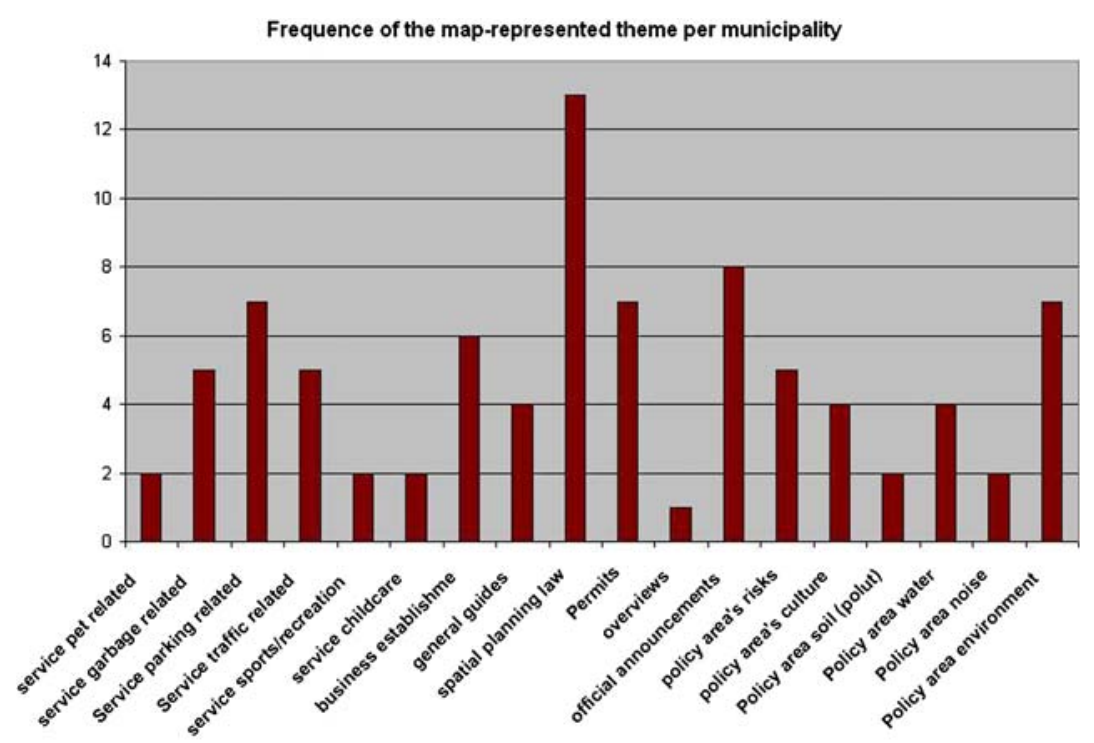

Figure 1. A classification by theme of the maps in official online publications of 200 local government websites. 
Just using 'a GIS standard' does not immediately solve all spatial problems; A problem in spatial planning is for instance that authorities may use different types of spatial references to legislate. Common base maps for spatial reference are satellite pictures, GPS signals collected by the local legislator himself, the normalised Grootschalige Basiskaart Nederland (Large Scale Basic Map of the Netherlands; GKBN), and cadastral maps of the Kadaster (property registration authority; French: cadastre, Lat: catastrum) or other maps based on the so-called Rijksdriehoeksstelsel (Realm's triangulation system). Note that for instance the base map of a building may also be used as a spatial reference system. In this case the building itself is identified by its address or parcel number on another, for instance the cadastral, base map. Essential is that we are linking objects that are not actually there, like a permit or a spatial planning constraint, to something which is actually there, like a geographical feature or a building.

Besides the inaccuracy of GPS and satellite pictures in general, ${ }^{4}$ the projection of such data from ellipsoid to the plane centered on the town of Amersfoort that the Rijksdriehoeksstelsel coordinates are displayed in, is a source of errors that can cause 'deformation gaps' in the legislator's maps.

Competent spatial legislators differ considerably in resources. The smallest municipalities sometimes leave spatial planning to one civil servant, and depend almost completely on services of commercial spatial planning bureaus.

GIS allow spatial planning maps to be joined automatically in a single model, and projection errors cause interpretation problems with users if maps overlap incorrectly. Theoretically these gaps may also create legal opportunities: an unregulated strip between two municipalities may be big enough to accommodate a railroad both municipalities don't want to allow in their territory. The popularity of technologies like Google Earth have the paradoxical effect that many legislators worldwide are moving away from a standardized coordinate system.

A more pressing concern is that even if it is possible to join maps and display similar geospatial normative objects (e.g. a number of local authorities declare a regime, linking zones designated residential area to certain land use restrictions, which are similar but not the same in these authorities, all to be communicated to the citizen by yellow polygons) in the same colour, the reality is that the norms connected to the object may differ considerably between territorial jurisdictions even if they are assigned the same colour. Each map is accompanied by its own regulations containing its own definitions and rules. Access to the associated regulations through the GIS is insufficiently standardised.

Things like a coordinate system must be fixed in additional standards. The standard coordinate system in the Netherlands is the ancient Rijksdriehoeksstelsel, and a classification of types of geospatial normative 
objects has been recently standardised through IMRO $^{5}$ (Informatiemodel voor de Ruimtelijke Ordening, in English: information model for spatial planning). While digitisation of spatial plans has been successful to the extent that most spatial legislators now offer digital material in the form of geospatial data it has not yet led to a degree of standardisation that makes joining maps in a GIS a point-and-click exercise for all involved stakeholders. There are even cases where a small municipality cannot access its own IMRO-compliant plans ordered from a spatial planning design agency because it does not have suitable software.

The DURP project has been running since 1998, and it is supposed to result in nationwide standardisation and electronic service in 2006. The new standardisation effort differs from the previous one in its involuntary nature. It will be embedded in the new Wet op de Ruimtelijke Ordening (WRO; spatial planning act), which will be republished in 2007.

Since the standard is compulsory, and the involved parties have made, and have to make, significant investments, designing a standard that is sufficiently stable for future requirements on electronic service is considered very important. At the same time, existing work based on the geospatial component of the standard should be preserved.

\section{Related work}

The market for geospatial data is growing, and the publicity around popular technologies like GoogleEarth keeps accelerating its growth. Geospatial data of governments finds its way into navigation software, real estate search engines etc. It is not surprising to learn that there are widely established international standards in this field.

Of special interest for the Netherlands are the initiatives by the EU and ISO. The European Committee for Standardisation (CEN, Comité Européen de Normalisation) set up a technical committee CEN/TC 287 - Geographic Information. This committee defined a set of eight European norms and published four European reports from 1992 to 1999 concerning geospatial data (e.g. spatial schema, quality, metadata, etc.).

The International Organisation for Standardisation (ISO) set up the technical committee ISO/TC 211 in 1995, absorbing the European work program of CEN. Currently, ISO has published some 20 standards in this area. These are commonly referred to as ISO 19000 series.

The eEurope 2005 Action Plan (eEUROPE, 2005) is a common initiative defined by the European Commission (EC). This plan aims at "developing modern public services and a dynamic environment for e-business through widespread availability of broadband access at competitive prices and a secure information infrastructure". The "Interchange of Data Between 
Administrations" (IDA, 2005) is a more general European program using advances in information and communication technology to support electronic exchange of information between public administrations across Europe.

The initiative Infrastructure for Spatial Information in Europe (INSPIRE) aims to:

create a legal framework for the establishment and operation of an Infrastructure for Spatial Information in Europe, for the purpose of formulating, implementing, monitoring and evaluating Community policies at all levels and providing public information. [..] INSPIRE focuses on environmental policy but is open for use by and future extension to other sectors such as agriculture, transport and energy. [..] INSPIRE will not set off an extensive programme of new spatial data collection in the Member States. Instead, it is designed to optimise the scope for exploiting the data that are already available, by requiring the documentation of existing spatial data, the implementation of services aimed at rendering the spatial data more accessible and interoperable and by dealing with obstacles to the use of the spatial data. INSPIRE will pave the road for a progressive harmonisation of spatial data in the Member States.

The INSPIRE proposal for a directive has been adopted by the EC in 2004 . According to the INSPIRE survey carried out in the spring of 2003 the Netherlands is the front runner in Europe in geospatial data warehousing and standardisation. This is not very surprising if one realizes that 16 million people have to share only 41,000 square $\mathrm{km}$ in this country, and the country has a long history in spatial planning.

International and national committees have started to define standards for management and exchange of geospatial data. The intention is to create a basis for eGovernment and eCommerce by standardisation of spatial datasets (e.g. cadastral information, road maps, power lines, etc.) and direct access to "data at the source" without local duplications. A large number of initiatives is mentioned in (Dorninger et al. 2004). Dorninger et al. (2004) also includes a comprehensive set of references to relevant technical documents. In the US (NSDI), Australia (ASDI), and Canada (CGDI) there are similar initiatives for making geospatial data collected and created by governments more accessible to business and public (cf. Hall and van Orshoven 2003).

The service platforms are already under development. The Global Spatial Data Infrastructure Association (GSDI) is worth mentioning, as well as the OpenGIS Consortium's Web Mapping Testbed project (WMT). ${ }^{6}$ 


\subsection{GEOGRAPHY MARKUP LANGUAGE}

The general XML standard for representation of geospatial data is the Geography Markup Language (GML) of the Open Geospatial Consortium. ${ }^{7}$

Geography Markup Language is an XML language defined in XML Schema for the modelling, transport, and storage of geographic information. The key concepts used by Geography Markup Language (GML) to model the world are drawn from the OpenGIS Abstract Specification and the ISO 19100 series of specifications.

GML provides a variety of kinds of objects for describing geospatial phenomena including features, coordinate reference systems, geometry, topology, time, units of measure and generalised values.

A geographic feature is a 'real world phenomenon' associated with a location relative to the Earth. So a digital representation of the real world can be thought of as a set of features. The state of a feature is defined by a set of properties, where each property can be thought of as a \{name, type, value\} triple.

The number of properties a feature may have, together with their names and types, are determined by its type definition. Geographic features with geometry are those with properties that may be geometry-valued. A feature collection is a collection of features that can itself be regarded as a feature; as a consequence a feature collection has a feature type and thus may have distinct properties of its own, in addition to the features it contains.

The triple model of GML naturally maps to the W3C's Resource Description Framework (RDF), and GML's serialisation profile 3 defines an RDF data model for GML. This means that geospatial objects in GML can be referenced by URI as RDF objects, which opens up interesting perspectives for the integration of ${ }^{\mathrm{META}}$ Lex XML and GML. The relation between ${ }^{M E T A}$ Lex XML and RDF will be discussed in Section 4.

\subsection{GEOSPATIAL INFORMATION AND THE LAW}

A major part of the high quality geospatial data used in GIS actually represents normative statements and positions (claims, titles) relating to space and not existing 'real' geographic features. This has consequences for representation and storage of this data (cf. Hess and De Vries 2004), that merits separate research into the relation between geospatial data and the law. Work in this area is fairly rare.

In (Kaza et al. 2004), Kaza discusses the common misunderstanding of equating a property right to a geospatial 'thing' in the context of GIS. Geospatial data capturing titles and responsibilities are often used by third parties as if they describe the things that are there. A property title and a 
building permit for instance become a house in the translation of a cadastral database of claims and titles to geospatial data used in GIS. For many areas of the world cadastral and urban development maps are simply the best source of descriptive information available about what the real situation on the ground might look like.

Within the academic spatial planning community there is some awareness of this problem, and there are attempts to capture this distinction between normative statements relating to space and real spatial objects.

A relevant avenue of research in the GIS area is the Planning Markup Language (PML; cf. Hopkins et al. 2003), an XML language for representation of plans and regulations in an urban planning context. The data model defined for this language is a potentially useful resource. It is clearly founded in a model of spatial planning as strategic decision making, and is unfortunately not informed by literature on representation of normative statements in legal theory and AI \& Law along the lines of (Alchourron and Bulygin 1981; Hansson 2001).

Initiatives in spatial planning often take the perspective of the spatial planner and not of the consumer of the spatial plan. The perception that legally enforced restrictions in spatial planning are somehow fundamentally different from 'normal' legislation is common in the spatial planning field, but that begs the question of why the citizen ought to have access to it to find out whether he can use land in a certain way: isn't that a straightforward legal issue that should be approached like other services of its kind in eGovernment? We think it is. Legislation should not be written for the benefit of legislative drafters, and spatial plans should not be designed for the benefit of the spatial planner.

It is possible to design and use spatial legislation in the exact same way as any other legislation, but convenient and efficient in many cases to exploit the advantages of spatial representation.

In the DURP project in the Netherlands some propose a radical break with the past practice of publishing maps accompanied by a regulation: instead of these old-fashioned instruments from the age of paper they propose that legislation associated to the map should come in the form of standardised GIS relational tables and a set of possible constraints. This proposal completely breaks down the distinction between legislation and the (formal or executable) representation of the contents of the legislation, which is in itself a good thing if it will require less interpretation of what the legislator means.

Breaking down this distinction creates problems in itself, however, since a move like this will require revision of centuries of legal theory on interpreting interrelated norms in documents and on the relation between documents and maps. Without detailed additional legislation on solving conflicts relating to these relational tables, administrative judges will face a greenfield situation, 
while the current political trend in the Netherlands is to require that the revision of an act results in a shorter document than the previous one. On the other hand, by not breaking down the distinction between original source and representation, representations will become a future source of conflict in administrative courts.

A second problem is that restricting the expressiveness of constraints that can be formulated in a specific formal language also restricts the legislative competence of municipalities and provinces, and the revision of the Dutch WRO act should not have that effect. Any standardisation will have to respect the legislative competence of the involved legislators.

This lack of expressiveness also affects the representation of existing legislation and jurisprudence, of course. In (Kaza et al. 2004), Kaza discusses the limitations of relational tables and constraints in relation to the rather complex relation between cadastral maps and social and legal realities on the ground: GIS mostly capture frontiers between areas and spaces, and frontiers have a social and legal - not a geographic - origin. Cadastral maps are in this context even relatively straightforward, since they are based on the welldeveloped concept of property.

The idea of moving the written regulations accompanying the GIS data into the GIS data illustrates the subservient role of the written regulations in the spatial planning field. In the broader legal field the view of spatial plans as a regulation with a map as an appendix dominates.

\subsection{THE LEGAL ATLAS}

A natural question is whether there are any interesting existing systems in the intersection of legal information systems and GIS. Such a system could serve as a source of inspiration of what a workable standard for legal-geospatial data looks like.

When one thinks of legal information systems, the first thing that springs to mind are dedicated legislation and case law text search engines, provided either by legal publishers or by national legislation portals. Secondly, we have the decision support system that guides the user to a deontological (allowed or disallowed) or derived teleological conclusion (e.g. eligibility for a benefit is the mere teleological correlate of a deontic duty - or maybe permission - to pay for the counterparty) using some question-answering paradigm (e.g. decision trees) usually involving yes/no questions an some numbers (age, income). In (Winkels et al. 1998) we defined legal information system (LIS) as a system that directly or indirectly answers deontological questions. In the case of text search engines, which return texts, you can define recall in terms of this criterium: do the returned texts answer the deontological questions of the user (correctly)? 
GIS systems have the obvious advantage over text based systems that images are processed more quickly than text. It provides a better overview, more comparability, more dimensions displayed simultaneously, and it is possible to combine GIS data with satellite overlays of Google Earth and other maps.

One of the authors of this paper did indeed publish on such a system: the Legal Atlas (cf. Peters and Van Engers 2004, Wilson and Peters 2004) of the ADDWijzer project. On a technological level the query language for map data described in (Hess and De Vries 2004) is even closer to the legal question-answering paradigm.

Figure 2 shows a screenshot of the first prototype of the Legal Atlas, which was not based on XML.

This first Legal Atlas system was able to relate legislation to geographical features in two ways:

- Spatial plans contain maps that directly classify geospatial objects in terms of a legal conceptual framework defined in the accompanying regulation. These classifications can be imported into the system, and linked to the relevant text fragments.

- Any other legislation can be linked to its territorial jurisdiction. This is not yet considered very useful for national legislation, ${ }^{8}$ but for local legislation it opens up a new way of accessing and comparing legal sources from local legislators.

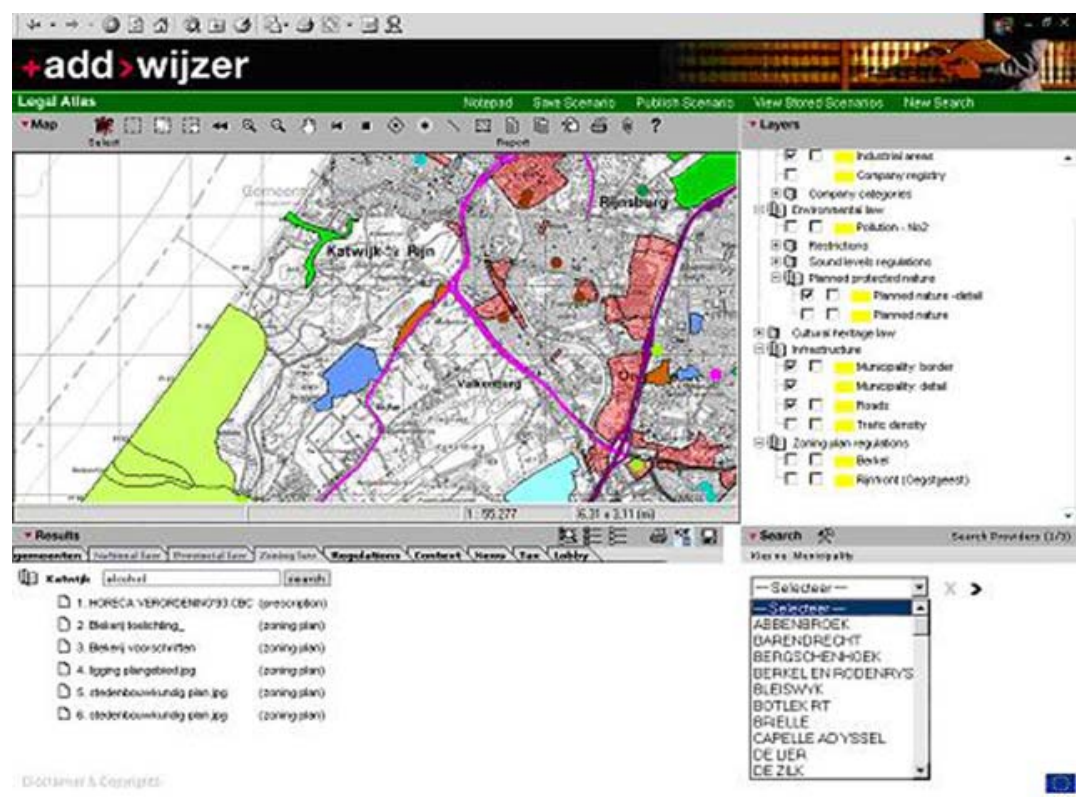

Figure 2. The ADDWijzer Legal Atlas browser for legislation limited in spatial scope. 
The system can show certain restrictions by means of filters that can be selected and deselected. Typical use scenarios of the system are for instance deciding where along the coast it is possible to organize a significant public event on or near the beach, or where along the A4 highway there is an area where it is possible to open an $\mathrm{LPG}^{9}$ station.

In the scenario of the public event the organisers involved in the ADDWijzer project stated that they end up in court because of violated legislation in almost $100 \%$ of the cases. They wanted to apply filters selecting areas where special municipal alcohol or soft drugs policies apply, areas subject to severe sound restrictions, and environmentally protected areas. The enforcement window depends on the municipality and is considered very relevant by the organisers. Organisers could proceed with violating the municipal regulations for as long as the time-window before actual enforcement allowed them to produce loud music etc. Most municipalities have a window of a couple of days. This is enough to have a good party. In consequence, the organisers needed to retrieve very specific procedural regulations per municipality. In addition, they wanted to correlate possible areas to economic parameters like road infrastructure, parking space, and nearby hotels and campaigns for tourists.

In the case of the LPG station the BOVAG, which is the automotive industry umbrella organisation, was faced with the problem of an increase of safety perimeters from 50 to 80 meters around the existing stations. This forced them to seek new locations for about 200 gas stations. The map interface of ADDWijzer enabled the BOVAG to seek and compare areas with a higher probability of success in overcoming legal barriers and political intentions of the regional authorities involved.

The regional coding scheme that associates legal sources with geospatial objects was developed in the DURP project. The uniquely detailed land zone information is based on the IMRO standard for spatial planning, which adheres to the NEN 1878 norm for data interchange.

IMRO, the information model for spatial planning, has hundreds of standardised land use codes which classify an area in terms of intended use. Each code is automatically related to a set of relevant zoning regulations and a policy document justifying zoning decisions. The fact that such a codification exists is meaningful for eGovernment in general for a number of reasons. The spatial planning eGovernment infrastructure of the municipalities becomes automatically updateable. Simulation of scenarios also becomes a lot easier. National law can also be translated to geospatial normative concepts and objects related to the codifications of land-use in municipalities: if, for example, the safety perimeter is changed by National Law from 50 to 80 meters around LPG stations, it has now become possible to show the local effects by plotting the increased perimeters on a map for every zoning area with this specific code and calculating consequences. 
The detailed codification is the first real attempt to enable users to express questions to a governmental agency about where one can perform certain activities. This is especially relevant for businesses. For people in the spatial planning field it is relevant because of the citizen-centred character of the approach: it is much more effective to plot a legal atlas than browsing 20 municipal websites and digging up the relevant regulation for the intended activity. The coding enables digital queries and constraints: "please show me all parking lots near industrial areas where the industrial hindrance level is greater than 3". For real estate brokers it becomes possible to make more educated guesses towards the future value of houses or cottages in recreational zones - zones in which permanent inhabitancy is specifically prohibited - if they can plot the concrete policies of regional authorities in combination with European national maps of cultural heritage (Malta treaty) and ecological infrastructure (Århus treaty). These maps helped to estimate which houses could get the status of permanent home, which multiplies the real estate value. The codes are now translated to GML rules which helps to create a more flexible and maintainable codification system.

The data in this first Legal Atlas prototype was supplied by the province of Zuid-Holland (South Holland) along the coast in the west of the Netherlands.

Projects like ADDWijzer demonstrate the usefulness and technical feasibility of useful Geographic-Legal Information systems, but the legal sources in the system still have to be carefully selected manually. The adoption of systems of this kind depends on the adherence of information providers to a representation standard that make these systems possible. XML, RDF, and OWL are ingredients of such a standard for GIS \& Law.

\section{Problems with GIS for legal use}

According to Dutch (voluntary) presentation standards, areas designated for residential use are displayed in yellow. Normally speaking one can assume that any area marked yellow means the same thing all else being equal. Of course there may be other rules in other spatial legislation that apply to some yellow areas and not to others. This is true at least within the same jurisdiction: to the city council evaluating a draft regulation including a map of its own jurisdiction, the meaning of yellow will be perfectly clear. The colour yellow can still mean completely different things in terms of actual restrictions on land use and construction in different jurisdictions. To a real estate developer using a GIS to find interesting locations in a fairly large area (e.g. the suburban areas of Amsterdam) the colour yellow is pretty much meaningless. The functional designations used in land zoning are logical from a policy point of view, but they give little information about the rules applicable in an area. Residential use is a functional designation part of a 
compulsory standard (IMRO), but the standard does not restrict legislators in designing their own rules. We do not advocate that the freedom of local legislators should be taken away - on the contrary - but the current practice of standardizing only functional designations is not as powerful for supporting eGovernment as it could be. The user of the GIS system should be able to infer from the information the system gives him that there are meaningful differences between yellow areas on his screen.

Suppose for instance that one wants to dig a swimming pool on one's land behind one's house. Making a swimming pool involves digging a hole, displacing or even removing the soil, and constructing a swimming pool. There are a number of completely different arguments why such an action may be disallowed:

- You do not hold the land surface of the parcel in fee simple absolute. The government, or in rare cases another party, may have rights over your land that prohibit you from digging a pool.

- You do not own the soil below the land surface of your parcel, or you do not hold it in fee simple absolute: The government, or in rare cases another party, may have rights over the soil below your land that prohibit you from digging a pool.

- You live in an area vulnerable to land loss where moving soil, even on your own land, is considered a felony.

- The Realm's Service for Archaeology has designated your parcel a potential iron age site, and you are not allowed to disturb the earth in any significant way.

- Your neighbours do not agree a swimming pool in your garden improves their view, and they have some nonpossessory interest in your land $^{10}$ that requires their permission.

- A neighbour has a right of passage, following from a covenant running with the land, and the swimming pool blocks the way.

- The municipality considers your garden part of a protected view, and does not allow significant changes.

A map designed for a more general purpose than answering this specific question is not of any help. We can certainly imagine generating the map layer that answers this question, but only if the data stored about applicable rules is more fine-grained than current GIS-based solutions generally allow. If the relevant information is not stored in this way, the user should still be able to find the answer by searching and accessing the associated regulations. In this case the relevant concepts are digging and construction.

Note that the first three arguments in the list can be variations on the same theme: in a polder landscape below sea-level where maintaining land is a costly, continuous, and collective enterprise, punishing "land theft", or 
government ownership of all land, or government ownership of land below the surface are different local solutions to the same problem. There are however also completely different reasons to choose the same legislative solution. ${ }^{11}$

The diversity of instruments solving the same societal problems does not make joining maps together any easier. Present-day GIS are not of much help in this case because they usually focus on classification by instrument: they merely distinguish various forms of land tenure from the government and ownership of land, even though both may be burdened with the same limitations. Classification by instrument is legislator-oriented, and not citizen-oriented. The solution is not to reduce the number of instruments, but to add more citizenoriented information connected to relevant events in the citizen's life.

Another problem with GIS systems is that they reify every right, permit, or burden as if it is attached to some geospatial object instead of a right holder. There is really a difference between a designation of a parcel of land as a zone for LPG stations, a designation of a structure on that land as an LPG station, and a permit issued to a present user running an LPG station in that location: the difference becomes apparent when the user of the land changes, or the structure disappears. A restriction on a parcel of land remains in existence until it is repealed or annulled by an act of the legal system, while a restriction on structures and natural persons can disappear because of external events.

The first major distinction re geospatial objects is whether the normative statement is attached to the land (or water) itself or to some construction on that land or water, and also whether and to what degree the construction is permanent (e.g. house, garden shed, tree, fence) and to what degree it is movable (e.g. house, trailer, houseboat, swivel bridge, ferry).

Another important distinction regarding restrictions attached to structures is whether some normative statement applies to a geospatial object directly (a burden on a property registered as a residence) or whether it applies to some geospatial object because it belongs to some class (the property automatically acquires or loses burdens because it is used as a residence). In the latter case changes in legal status occur autonomously, without any action by the legal system. Another complication is that it requires interpretation: residence and LPG station may seem clear, but what is a 'major educational institution' in a provision (taken from (Kaza et al. 2004) that states that alcoholic beverages cannot be sold within $75 \mathrm{~m}$ of a major educational institution?

There may also be conditional rights attached to a right holder in relation to some geospatial object dependent on some other right holder: a grazing right can be exercised only after a harvest, performed by the harvesting right holder, and only if the land is farmed. Grazing rights may also be only valid when the right holder makes a living tending livestock. These rights are 
traditionally hereditary, although hereditary rights of this nature - the more comprehensive ones that restricted the government in any case - have largely disappeared in the Netherlands through a combination of legislation, negotiation, and force by the government in the late 19th and early 20th century. Note that in principle a hereditary right that has been dormant for generations may resurface at a legally opportune moment if someone decides to take up an old profession like herding lifestock.

\subsection{SHORTCOMINGS IN GIS-BASED PROPOSALS FOR SPATIAL PLANNING}

Standardisation of spatial planning is very much approached from a GISbased perspective as we showed in the previous section. The major shortcoming of these proposals is that they fail to recognize the general requirements for managing text-based legislation.

In (Boer et al. 2004) we have discussed for instance version management for legislation content management systems extensively: present content management systems fall short of these requirements, but in spatial planning these requirements are even almost forgotten. Many feel that this cannot possibly be a major problem; Administrative courts disagree, since a great amount of 'merely formal' cases they deal with concern questions of validity of legislation of lower legislators. It should be clear whether a land use restriction replaces earlier ones on the same parcel of land. Issues like retroactive and delayed application of new rules, as well as the distinction between old and new cases in application of rules are another source of error and confusion.

Other recommendations we made deal with analogies in spatial planning of 'tricks' for finding legislation in search engines. We have been creating awareness of issues such as competence and delegation of competence, and assignment of identity to the regulation, which were important in discussions on standardisation of legislation in general (Winkels et al. 2003). Competence as a structuring device is underestimated: after keyword search, the legislation based on this act option (which is often mistaken for a kind of handcrafted topics index) appears to be the most used option in the national search engine. $^{12}$

Another interesting issue is seducing the legislative drafters into using model sentences, and teaching them to deviate from model sentences by explicitly making them more specific or more general, and adding exceptions. This has the potential of turning into a subsumption hierarchy between norms along the lines of (Boer 2000; Winkels et al. 2002). Model sentences are recurring grammatical patterns used extensively by legislative drafters on the national level. Using the same pattern again is advantageous because it is a hint to the courts what reading of the sentence is intended by the legislator. Municipal regulations largely lack such predictability in use of language. 


\section{Linking geospatial data to OWL and}

An interesting question is whether spatial regulations can be captured in META Lex XML, which claims to be jurisdiction and domain-independent. The answer is yes. Translating spatial regulations to ${ }^{\text {META }}$ Lex is straightforward and linking geospatial references to ${ }^{\text {META }}$ Lex XML is not at all hard if RDF - which is supported by both ${ }^{\mathrm{META}}$ Lex and GML - is used as a common platform.

${ }^{\text {META }}$ Lex XML standardizes structure and designation of identity of legislation. It treats legislation as a document, and any other attached materials, like tables, as unstructured appendices to the document. Any ${ }^{\text {META }}$ Lex XML structure can be translated with the standard ${ }^{\text {META }}{ }^{2}$ ex XSL transformation to RDF conforming to the META Lex Web Ontology Language (OWL) schema.

Figure 3 shows the relationship between the XML Schema-based and RDF Schema-based encoding of the same document. Both schemas define the same constraints, but RDF is based on a data model that is more flexible for use in applications.

Defining legislation-related concepts for different jurisdictions in a single RDF dictionary makes it easier to identify similarities and differences between legislative documents. The ${ }^{\text {META }}$ Lex schema can be integrated in such dictionaries as a 'generic backbone' that can be exploited by META Lex-aware tools. This allows to for instance define principles like Lex Posterior (the later

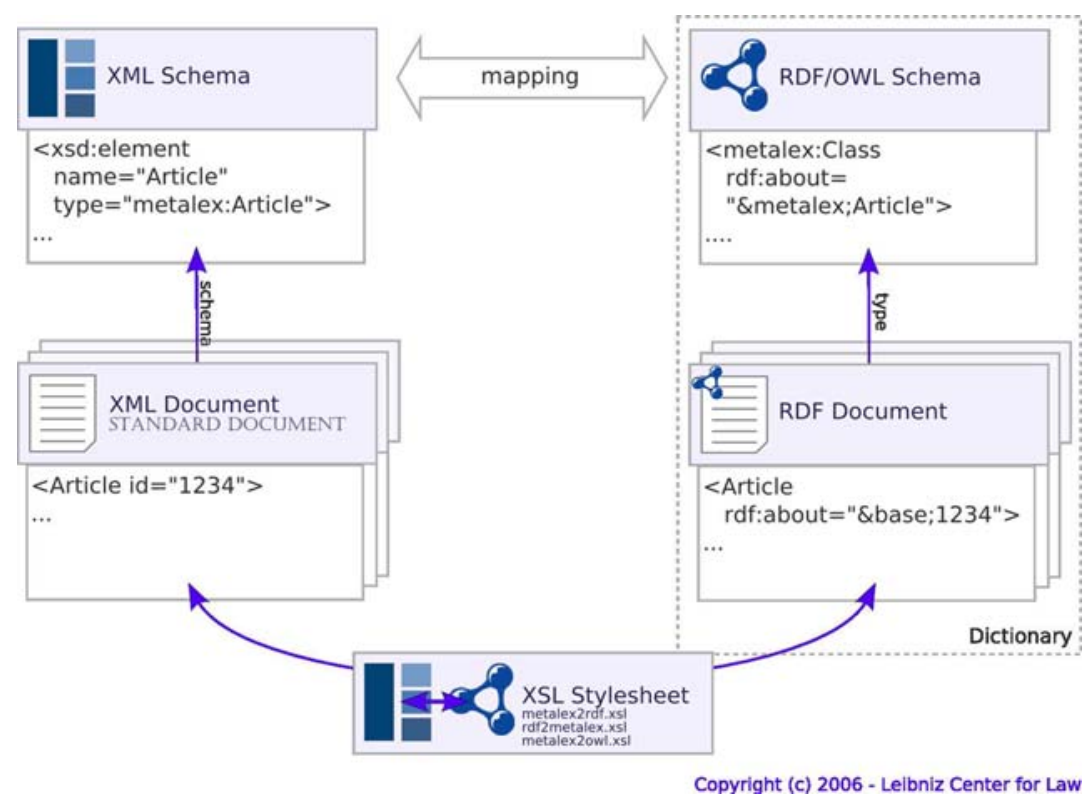

Figure 3. RDF representation of legal documents. 
law defeats the earlier one) directly in terms of the structural parts of the legislative document and their attributes.

The parallel representation of legislation structure in RDF and XML also serves another function: legislative XML as produced by a publications office will generally steer clear of adding information that can be construed as an authoritive interpretation of the normative contents of legislation. Large user organisations - like a tax administration - may want to add such interpretations in the form of a knowledge representation that serves as the input to expert systems used inside the organisation. But they will generally speaking not want to directly embed it in the legislative XML, or even link it to the URI of a part of such a document, because that creates unnecessary maintenance if the XML documents - or worse: the schema or the URIs - are updated by the producer. ${ }^{\text {META }}$ Lex RDF functions as an intermediary format for reasoning about (the structure of) a document without actually opening it, or even directly referring to its structural parts.

There is a clear need for the standardised method ${ }^{\text {META }}$ Lex provides for linking knowledge representations of the meaning of legislation in OWL to the legislation qua document, without embedding it in it. This issue is described in more detail in (Boer et al. 2004).

META Lex RDF can be used with extensions in the form of standardised RDF or OWL schemas to cater for specific user communities using ${ }^{\text {META }}{ }^{\text {Lex. }}$. The spatial planning field is obviously a good empirical testbed for this theoretical feature.

There is a consensus in DURP that the GIS aspect of spatial regulations should be represented in GML 2.0, using the existing IMRO scheme. IMRO is based on the GML data model, and therefore completely compatible with GML. IMRO (and the GIS field in general) is a good example of the thesis that a shared abstract data model (which is the philosophy RDF is based on) can be as valuable or even more valuable than a shared syntax, such as XML.

GML provides a variety of kinds of objects for describing geographical features and related phenomena. The state of a feature is defined by a set of properties, where each property can be thought of as a \{name, type, value\} triple, and GML can also be easily rendered as an RDF data model, which is also triple-based. This is the so-called profile 3 serialization of GML. By treating both GML and ${ }^{\text {META }}$ Lex as RDF data, the integration problem is reduced to a matter of defining an OWL schema for the objects mediating between the legislative text and the geospatial object.

${ }^{M E T A}$ Lex is based on a distinction between materials associated to the document, being its appendices, and the interpretations of what the regulation means. These are linked in a different way: the link between documents is simply one between parts and wholes, while the interpretation constitutes an alternative representation of the document. 
Typical of spatial planning regulations is that legal concepts such a residential function are defined in an extensional way in the map, by explicitly pointing out to which geospatial objects it applies, as opposed to normal legal concepts, which usually acquire meaning from an intentional definition. No interpretation is necessary or possible: a geospatial object only acquires the classification residential by explicit assignment by the competent authorities. Both from the interpretation point of view and the appendix point of view this is exceptional.

While it is in principle possible to let people decide for themselves how this information is attached to ${ }^{\mathrm{META}}$ Lex regulations - there are no technical impediments after all - we have designed two extensions in the form of an OWL schema for this purpose:

The Legal Atlas ontology: This ontology defines the general mechanism by which a source of law refers to either a class of geographical objects, specific geographical objects, a class of geospatial normative objects, or a specific geospatial normative object.

The IMRO ontology: This ontology implements the IMRO information model for spatial planning of the government of the Netherlands in OWL and uses the concepts of the Legal Atlas ontology.

The Legal Atlas ontology is intended as a generic adapter for GIS applications to understand domain-specific spatial planning ontologies like IMRO. As a proof of concept the second prototype of the Legal Atlas has been partially reimplemented in Java, based on an RDF store (Jena ${ }^{13}$ ) and an OWL DL reasoner $\left(\right.$ Pellet $\left.^{14}\right)$. The new Legal Atlas has two basic functionalities: it can show to which geospatial objects a concept in the legal source applies, and it can show which (parts of) legal sources apply to some selected geospatial object. The selection process is performed by SPARQL queries based on the classes of the Legal Atlas ontology. Figure 4 shows a screenshot of the new Legal Atlas. It will be made available for downloading through the ${ }^{\text {META }}{ }^{\text {Lex }}$ website. We are gradually expanding the use of OWL reasoning to cover GML notions: if for instance an area $\mathrm{A}$ includes area $\mathrm{B}$, then the norms applicable in A are applicable in B. But this is an ongoing project. Work of this nature has already been done in the Cadastral domain (cf. Hess and De Vries 2004). The intention is to define as much of spatial semantics in OWL as possible. OWL has a number of wellknown drawbacks for the definition of spatial (and temporal) semantics: it is nor very good with numbers, and cannot the express reflexivity of properties (cf. generally Grau et al. 2005).

The application of ${ }^{\text {META }}$ Lex to the geospatial domain has also led to a change of ${ }^{\mathrm{META}}$ Lex itself. Version 1.3 now uses an attribute region, with a URI, to refer to the region to which the source applies. This is to be distinguished from references in the content of the legal source to geospatial objects or classes of objects. The presence of this simple attribute will 


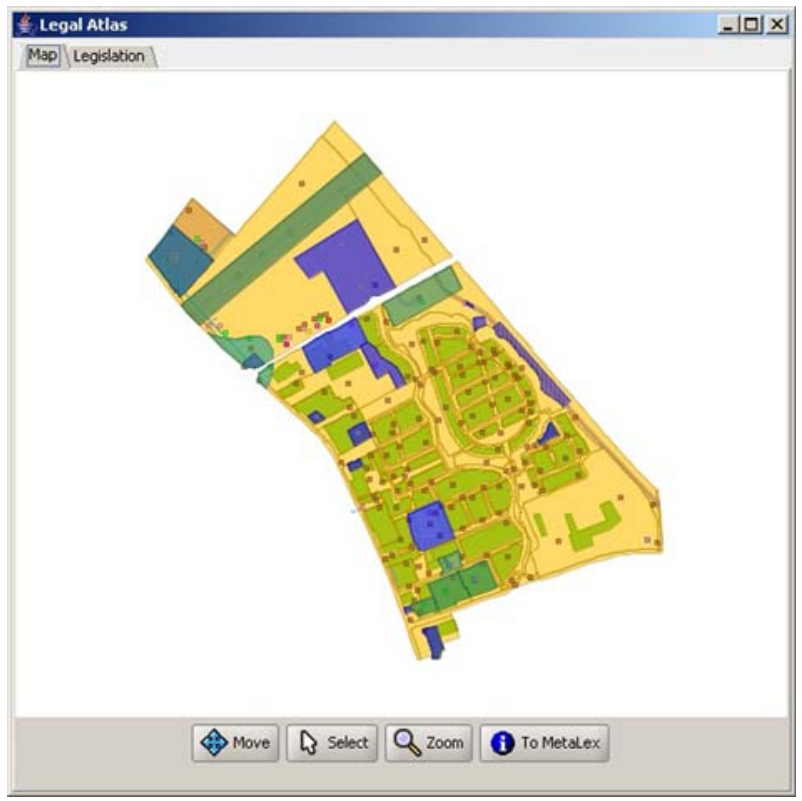

Figure 4. The new Legal Atlas based on ${ }^{\text {META }}$ Lex, GML, and RDF. The screenshot shows a shape file (also supported) because real spatial plans conforming to the IMRO2006 standard, which requires use of GML2.0, are not yet available.

hopefully encourage legislators to define and make available information about their spatial jurisdiction in GML and OWL.

\subsection{SPATIALLY REFERENCED NORMS IN GIS}

One of our roles in the DURP project is to create awareness of the way spatial regulations map to the more traditional interpretation of law as natural language describing norms. In this context, we discussed a number of examples of visualisations of normative statements in space. The examples evoke the idea of a emphspatial-deontic logic based on being in or out of spatial norm objects, that can be described in OWL.

In rare cases it is possible to display a normative statement in its full effect. Maximum roof height can be displayed directly, for instance. In other cases it is possible to display the geospatial normative object - any set of normative statements that refers to a geospatial object or a set of geospatial objects. Use restrictions are for instance bundled in the assignment of functions to spaces.

Figure 5 shows a bird's view of designated functions, and maximum roof height and roof base height in an area in the center of Leeuwarden. Figure 6 shows a side view of the area shown in figure 5. Note the underground parking that is not visible in the bird's view. These visualisations only display what is allowed to be there, but this happens to overlap significantly with 


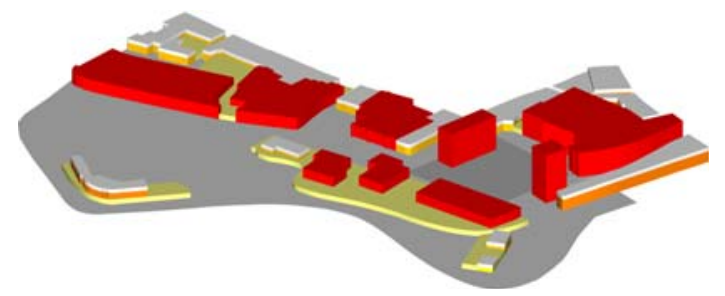

Figure 5. Bird's view of designated functions, and maximum roof height and roof base height in an area in the center of Leeuwarden.

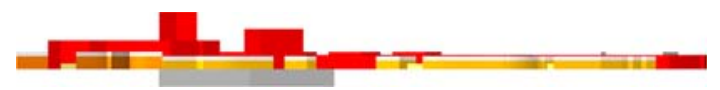

Figure 6. Side view of the area shown in Figure 5. Note the underground parking that is not visible in the bird's view.

what is there. The fact that the Netherlands is mostly flat makes generating these three-dimensional visualisations based on two-dimensional data easy.

These views make it possible to show something that is not apparent from a traditional two-dimensional top view: functional designations can also be stacked. Figure 7 shows the functional layers in the high building area in figure 5 with the underground parking garage permission in a schematic way. These functional layers range from -12 to 20 meters. If we select this building through the map view, we are cutting through a number of layers with completely different functions - residential, retail, and parking - and associated use restrictions.

An inhabitant of one of the apartments on the top floor is maybe better off selecting the space he is interested in by address or parcel number (the

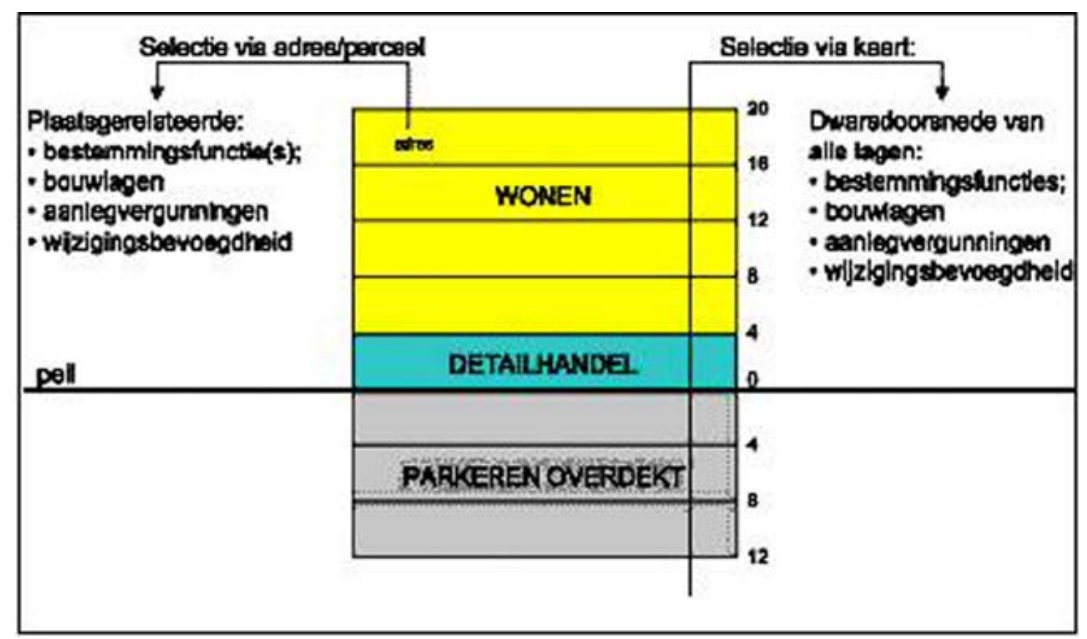

Figure 7. Layers in the high building area in Figure 5 with the underground parking garage permission. 
registration number of the parcel at the Kadaster land titling administration). Although skyscrapers are relatively rare in the Netherlands ${ }^{15}$ it is clear that the two-dimensional map view cannot communicate function assignments in inner cities - where the combination of retail and residential zones in one place is the rule - very well.

If one visualizes the current or a planned situation as well, it is possible to do a visual assessment of compliance with the norms. figure 8 shows a three dimensional representation of the shape of a construction plan or an existing building at the site. Testing the construction plan in figure 8 against the rules of figure 5 comes down to testing whether the building in figure 8 fits completely inside the area in which construction is allowed: because we see a dark block sticking out in figure 9, the construction is not allowed.

There are limits to what can be visualised in a single display. The most common restrictions can be displayed by a convex polyhedron, which either visualize a space in which things are allowed, or a space in which things are disallowed. Suppose it is for instance not allowed to cover more than $30 \%$ percent of a parcel one owns with constructions blocking the flow of water. The areas this rule applies to can be displayed, but the rule itself cannot be visualised. Both construction and use restrictions can be displayed this way, but not always in the same display.

Other common restrictions are for instance roof slope and roof type (hip, gable, hip on gable, crossed hip etc.), and colour schemes allowed. Generally speaking one cannot display disjunctions in restrictions effectively: the requirement of a hip roof can be displayed, but a requirement of either a hip

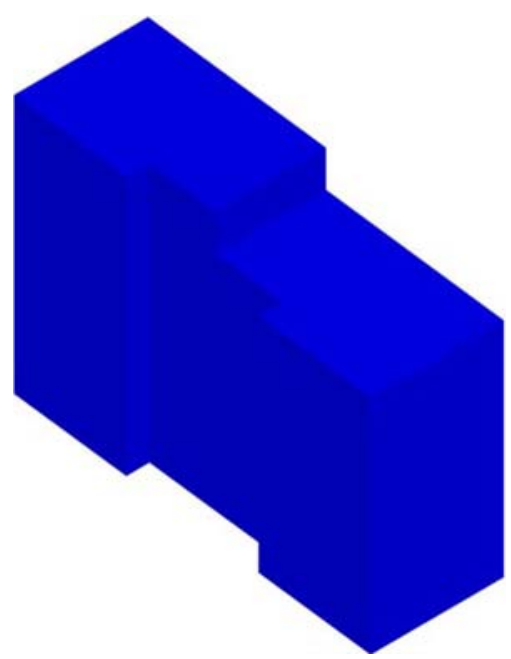

Figure 8. 3D representation of the shape of a construction plan (or an existing building). This dark-coloured shape will be tested against the spatial representation of building constraints in Figure 9. 


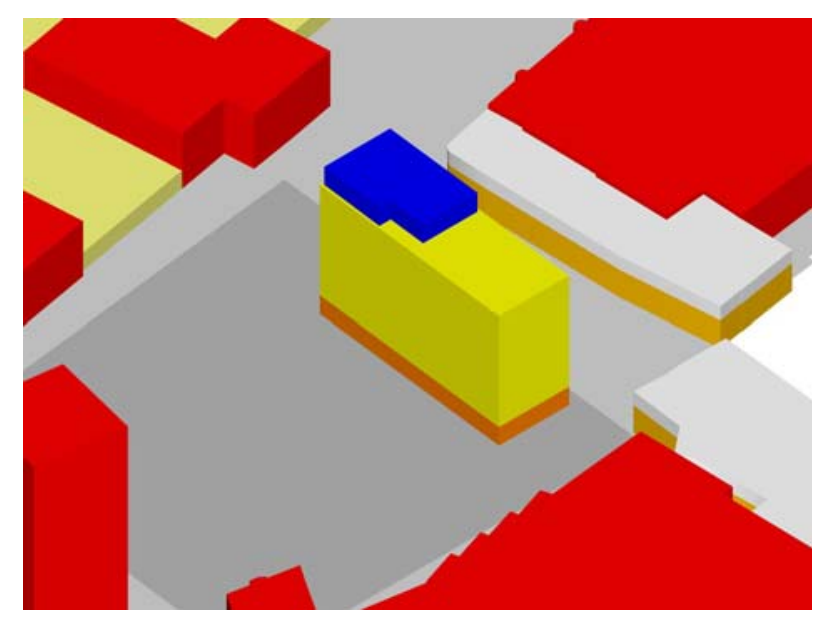

Figure 9. Testing the construction plan in Figure 8 against the rules of Figure 5: if we see the dark-coloured object, then it is not allowed. This image was taken with permission from Buro Vijn (http://www.burovijn.nl), a spatial planning consultant involved in the DURP project.

or a gable roof cannot. The maximum roof slope usually follows from the maximum roof top and roof base restrictions that are already shown in figure 5 for the lower buildings. High buildings usually have flat tops. A representative roof slope can be visualised by making the assumption that people will tend to maximize the space they can use. The visualisation fails to communicate in such a case that a flat top is disallowed, and that the roof slope may also be subject to a minimum.

In addition to the spaces and areas defined by convex polyhedrons and convex polygons, there are also some other relevant spatial primitives that can be displayed and automatically tested; The radius-based restriction is usually attached to a construction. This means it is usually a scaled polyhedron based on the dimensions of the construction to which it is attached. It may for instance be used as a basis for entitlement to a sound isolation subsidy because of noise levels (e.g. around a road) or designate danger zones (e.g. around a LPG gas station for instance). A path between points may also be used to display requirements such as a line of sight that must be free of obstacles, or a path between two antennas that must be free of obstacles blocking the signal. A more complicated spatial object is the cone anchored on a point that defines the field of coverage of artillery. Archaic restrictions may stipulate that in such an area houses can only be constructed from wood.

For spatial legal reasoning it is of course important to take the importance of frontiers between geospatial objects, overlaps, and inclusions into account and assign a logical meaning to them.

A polyhedron or polygon can be completely included within another polyhedron or polygon, and one geospatial normative object - represented by 
a set of complex polyhedra - can be completely included in another geospatial normative objects. The effects of normative objects that overlap in any way are of course added together. In the (rare) case that one finds conflicting but otherwise equal restrictions on objects that include each other, the smallest object represents a local exception in the sense of (Winkels et al. 2002; Boer 2000).

The idea of spatial exceptions is very interesting, but too contrived to be taken seriously as a design paradigm for legal GIS systems. The representation in OWL or a deontic logic of the spatial interpretation of the Lex Superior principle (viz. Winkels et al. 2002) is however worth a future publication.

\section{Discussion and conclusions}

Online maps are very important to citizens searching for information on legal restrictions at the local municipal level. This is therefore an area of eGovernment that attracts attention of eGovernment programme leaders and agencies that are involved in standardisation.

Developments in legal culture over time have created both differences evidenced in terminology as well as the widely spread opinion that spatial plans are not "real" legislation - as well as resemblances between the domain of spatial planning and the regular legal domain. Stakeholders involved in the domain of spatial planning have traditionally focused on the map as a binding element for connecting the actual norms to geospatial objects, geospatial objects to each other, and indirectly regulation to regulation. The introduction of ICT and especially the development of eGovernment, has created the awareness that standardisation and digitisation can improve effectiveness as well as efficiency of processes in the spatial domain.

Except for the specific map-oriented visualisation no objective grounds can be found to treat spatial regulations differently. As a consequence of this we can reuse the standards and tools that are being developed (or will be developed in the future) for the regular legal domain. Of course, extensions are made in order to be able to address the specific spatial features of norms, and the way citizens use these as an effective selection criterium for searching legislation. Various standardised tools for presenting (digital) maps exist in the GIS field, and connecting norms to map-based visualisations is still a relatively young area.

The Leibniz Center for Law has developed the META Lex standard to provide a generic solution for exchanging legal sources. Only minimal extensions to this standard were needed in order to cover spatial regulations. We expect that integration of ${ }^{\text {META }}$ Lex with GIS-standards will improve government effectiveness - certainly on the lower levels - and this will help us 
and others to create user friendly legal services and eGovernment applications for both citizens and civil servants. More difficult than extending the ${ }^{\text {META }}$ Lex standard this way will be changing the current legal culture in this specific legal domain.

Both standards and minds are like parachutes in that they work best when open. This makes the work of the DURP project, and continuing the "multicultural" work of the ADDWijzer project, so challenging. Many different stakeholders - city councils, legal drafting departments, spatial planning design bureaus, and civil servants involved in delivering services to the public - have to adapt their mental models, and this will take time.

\section{Acknowledgements}

The images in figures 5-9 were taken with permission from map data manually enriched by Buro Vijn (http://www.burovijn.nl).

\section{Notes}

1 http://www.metalex.eu

${ }^{2}$ http://www.addwijzer.info (eContent Programme)

3 http://www.overheid.nl

${ }^{4}$ They are never accurate below $50 \mathrm{~cm}$ and usually granularity is even less.

${ }^{5}$ See http://www.ravi.nl

${ }^{6} \mathrm{http} / / /$ ip.opengis.org/archive/wmt/

7 OGC; http://www.opengeospatial.org

${ }^{8}$ Given the limited mobility of citizens.

9 Liquefied petroleum gas.

${ }^{10}$ In the Netherlands this is typically in the form of so-called 'covenants running with the land' filed with the property title at the Kadaster.

${ }^{11}$ Common rationales for selective or complete public ownership of land are for instance nationalisation of valuable mineral supplies in the public interest, or the economic theory called 'Georgism'.

${ }^{12}$ http://wetten.overheid.nl

$13 \mathrm{http}: / /$ jena.sourceforge.com

${ }^{14}$ http://www.mindswap.org/2003/pellet/

15 Mostly because of legal restrictions on height.

\section{References}

Alchourron, C. and Bulygin, E. (1981). The expressive conception of norms. In Hilpinen, E. (ed.), New studies in Deontic Logic. Dordrecht, 95-124, D. Reidel.

Boer, A. (2000). The Consultancy Game. In Breuker, J., Leenes, R. and Winkels, R. (ed.), Legal Knowledge and Information Systems (JURIX-2000). Amsterdam, 99-112, IOS Press. 
Boer, A., Hoekstra, R., Winkels, R., van Engers, T. and Willaert, F. (2002). META lex: Legislation in XML. In Bench-Capon, T., Daskalopulu, A. and Winkels, R. (ed.), Legal Knowledge and Information Systems (Jurix 2002). Amsterdam, 1-10, IOS Press.

Boer, A., van Engers, T. and Winkels, R. (2003). Using Ontologies for Comparing and Harmonizing Legislation. In Proceedings of the International Conference on Artificial Intelligence and Law (ICAIL), Edinburgh (UK), ACM Press.

Boer, A., Winkels, R., van Engers, T. and de Maat, E. (2004). A Content Management System based on an Event-based Model of Version Management Information in Legislation. In Gordon, T. (ed.), Legal Knowledge and Information Systems. Jurix 2004: The Seventeenth Annual Conference. Amsterdam, 19-28, IOS Press.

Dorninger, P., Kippes, W. and Jansa, J. (2004). Technical Push on 3d Data Standards for Cultural Heritage Management. In Schrenk, M. (ed.), Proceeding of the 10th International Conference on Information and Communication Technology in Urban Planning and Spatial Development and impacts of ICT on Physical Space. Wien, Austria.

Grau, B. C., Horrocks, I. and Parsia, B. (2005). Online proceedings of the first owl: Experiences and directions workshop. http://www.mindswap.org/2005/OWLWorkshop/accepted.shtml.

Hall, M. and van Orshoven, J. (2003). Spatial data infrastructures in Australia, Canada, and the united states. Commissioned by the eu, in the framework of the inspire initiative, KU Leuven (SADL + ICRI).

Hansson, S. O. (2001). The Structure of Values and Norms. Cambridge University Press: UK.

Hess, C. and de Vries, M. (2004). From models to data: a prototype query translator for the cadastral domain. In Electronic Proceedings of the Workshop on Standardization in the Cadastral Domain, Bamberg, Germany.

Hopkins, L., Kaza, N. and Pallathucheril, R. (2003). Planning Markup language: Representing the Meanings of Plans and Regulations. In Proceedings of the AESOP/ACSP Joint Conference, Leuven, Belgium.

Kaza (2004). Spatial representation of property rights: Considerations on doxastic and epistemic systems. In Geog495B\&M: GIS and Society.

Peters, R. and van Engers, T. (2004). The Legal Atlas: Map-based Navigation and Accessibility of Legal Knowledge Sources. Knowledge Management in Electronic Government; 5th IFIP International Working Conference, KMGov 2004, Krems Austria, Springer Verlag, ISBN 3-540-22002-X, pp. 212-220.

Wilson, F. and Peters, R. (2004). Mapping the Law: Knowledge Support for Business Development Enquiry. In Proceedings of the eChallenges 2004 Conference, IST Programme, Vienna.

Winkels, R., Boer, A., Breuker, J. and Bosscher, D. (1998). Assessment based Legal Information Serving and Co-operative Dialogue in CLIME. In Hage, J., Bench-Capon, T., Koers, A., de Vey Mestdagh, C. and Gütters, C. (ed.), Proceedings of JURIX-1998.. Netherlands, 131-146, Nijmegen.

Winkels, R., Boer, A. and Hoekstra, R. (2002). CLIME: Lessons learned in Legal Information Serving. In van Harmelen, F. (ed.), Proceedings of the European Conference on Artificial Intelligence Lyon. Amsterdam, 1-2, IOS-Press.

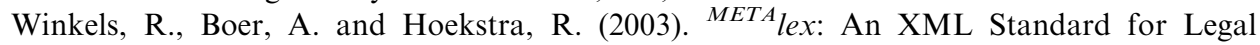
Documents. In Proceedings of the XML Europe Conference, London (UK). 